BAKTIMAS

Jurnal Pengabdian pada Masyarakat
Vol. 1, No. 4,

Desember 2019
eISSN 2685-113x

pISSN 2685-0303

\title{
Penyuluhan Wirausaha Home Industry Untuk Meningkatkan Ekonomi Keluarga Dengan Daur Ulang Barang Bekas
}

\author{
Denok Sunarsi ${ }^{1 *}$, Endang Kustini ${ }^{2}$, Asep Muhammad Lutfi ${ }^{3}$, \\ Rini Dianti Fauzi ${ }^{4}$, Noryani ${ }^{5}$ \\ 1,2,3,4,5 Program Studi Manajemen, Fakultas Ekonomi, Universitas Pamulang \\ J1. Surya Kencana No.1, Pamulang Barat, Kec. Pamulang \\ Kota Tangerang Selatan, Banten 15417 \\ *Penulis Korespodensi: denoksunarsi@unpam.ac.id \\ DOI : 10.32672/btm.v1i4.1720
}

\begin{abstract}
ABSTRAK
Tujuan dari kegiatan pengabdian kepada masyarakat ini adalah untuk menumbuhkan jiwa wirausaha skala home industry untuk meningkatkat ekonomi keluarga masyarakat Desa Cidokom. Selain itu juga untuk menggerakkan masyarakat sekitar agar sadar menjaga kebersihan dan kesehatan lingkungan dengan sadar pengelolaan sampah yang baik dan benar. Metode pengabdian dengan penyuluhan, diskusi dan tanya jawab serta praktek langsung pengolahan barang bekas menjadi barang yang bernilai ekonomis. Hasil kegiatan ini diharapkan dapat turut berkontribusi membangun desa Cidokom melalui ibu-ibu PKK nya berbagi pengetahuan, mendorong masyarakat untuk pengembangan sumberdaya yang dimiliki secara berkelanjutan untuk meningkatkan ekonomi keluarga. Wirausaha home industry daur ulang barang bekas ini dimaksudkan dapat memberikan motivasi bagi masyarakat untuk meningkatkan kemampuannya dan berkarya sehingga mendatangkan manfaat bagi dirinya dan masyarakat sekitar.
\end{abstract}

\section{Kata Kunci: Wirausaha, Home Industry, Ekonomi Keluarga}

\begin{abstract}
The purpose of this community service activity is to foster entrepreneurial spirit of home industry scale to improve the family economy of Cidokom Village community. In addition, it is also to move the surrounding community to be aware of maintaining environmental hygiene and health by being aware of good and correct waste management. Dedication method with counseling, discussion and question and answer as well as direct practice of processing used goods into items of economic value. The results of this activity are expected to contribute to building the village of Cidokom through its PKK mothers sharing knowledge, encouraging communities to develop their resources in a sustainable manner to improve the family economy. The home industry entrepreneur used to recycle used goods is intended to provide motivation for the community to improve their abilities and work so as to bring benefits to themselves and the surrounding community.
\end{abstract}

Keywords: Entrepreneurship, Home Industry, Family Economy 
BAKTIMAS

Jurnal Pengabdian pada Masyarakat
Vol. 1, No. 4,

Desember 2019
eISSN 2685-113x

pISSN 2685-0303

\section{PENDAHULUAN}

Sampah yang di daur ulang dan diberdayakan dapat menjadi peluang atau berpotensi menjadi dapat meningkatkan ekonomi keluarga. Persediaan barang bekas tidak perlu dikhawatirkan, hanya bermitra dengan bank sampah, maka barang bekas akan sangat mudah diperoleh. Jika barang-barang bekas ini dimanfaatkan dan didaur ulang sedemikian rupa, selain mendatangkan manfaat dan meningkatkan ekonomi keluarga, juga membantu mengatasi permasalahan sampah yang menjadi pekerjaan rumah (PR) bagi suatu pemerintahan terutama kota-kota besar di Indonesia.

Sekarang ini sudah banyak pelaku home industry daur ulang barang bekas, karena masyarakat sudah mulai sadar tidak mudah mendapatkan pekerjaan ditengahtengah pesaing yang sangat kompetitif. Meskipun untuk menjadi wirausahawan tidak cukup hanya bermodalkan tekat menjadi wirausahawan tetapi butuh komitmen dan motivasi untuk menjadi wirausahawan. Karena untuk merintis usaha atau membuka usaha home indutry tidaklah semudah membalikan telapak tangan. Jatuh bangun dalam usaha itu hal yang sangat wajar, dan butuh tekat yang sangat kuat untuk tetap eksis, apalagi bahan bakunya barang bekas, terkadang masyarakat masih memandang rendah hasil karya yang berbahan baku barang bekas.

Penyuluhan wirausaha home industry untuk meningkatkan ekonomi keluarga dengan daur ulang barang bekas, hadir untuk memberikan pengetahuan, wawasan dan peluang yang sangat potensial dikembangkan, karena bahan bakunya murah dan mudah diperoleh. Obyek pada kegiatan pengabdian kepada masyarakat ini adalah pada ibu-ibu PKK RT.04 RW 03 Desa Cidokom Kecamatan Gunung Sindur Kabupaten Bogor Jawa Barat, karena pengusul pengabdian kepada masyarakat melihat potensi local baik dari sumber daya manusia yaitu ibu-ibu rumah tangga dan bahan baku dari barang bekas yang mudah dan murah diperoleh sehingga sangat memungkinkan untuk dikembangkan guna meningkatkan ekonomi keluarga masyarakat setempat. Tujuan dari penyuluhan wirausaha home industry untuk meningkatkan ekonomi keluarga dengan daur ulang barang bekas agar masyarakat setempat dapat meningkatkan ekonomi keluarga dengan berkreasi, berkarya dan berdaya juang untuk mengubah barang bekas yang tidak bernilai secara ekonomis menjadi barang yang bernilai guna serta bernilai ekonomi tinggi.

\section{METODE PELAKSANAAN KEGIATAN}

Metode pelaksanaan memaparkan tahapan yang perlu dilakukan mulai dari perencanaan/ pengusulan hingga pelaporan dalam saru rangkaian kegiatan pelaksanaan pengabdian kepada masyarakat. Metode pelaksanaan dalam kegiatan pengabdian kepada masyarakat ini diawali dengan melakukan survey lokasi di desa Cidokom Kecamatan Gunung Sindur Kabupaten Bogor atas ketertarikan tim pengusul berdasarkan pengamatan sehari-hari, waktu kaum ibu-ibu habis untuk aktivitas yang kurang bermanfaat dalam kesehariannya, seperti main ke tetangga begitu anak sudah berangkat sekolah dan suami berangkat kerja. Adapun tahapan pelaksanaan program pengabdian kepada masyarakat sebagai berikut:

Metode pelaksanaan program pengabdian kepada masyarakat sebagai berikut: 
Denok Sunarsi, Endang Kustini, Asep Muhammad Lutfi, Rini Dianti Fauzi, Noryani

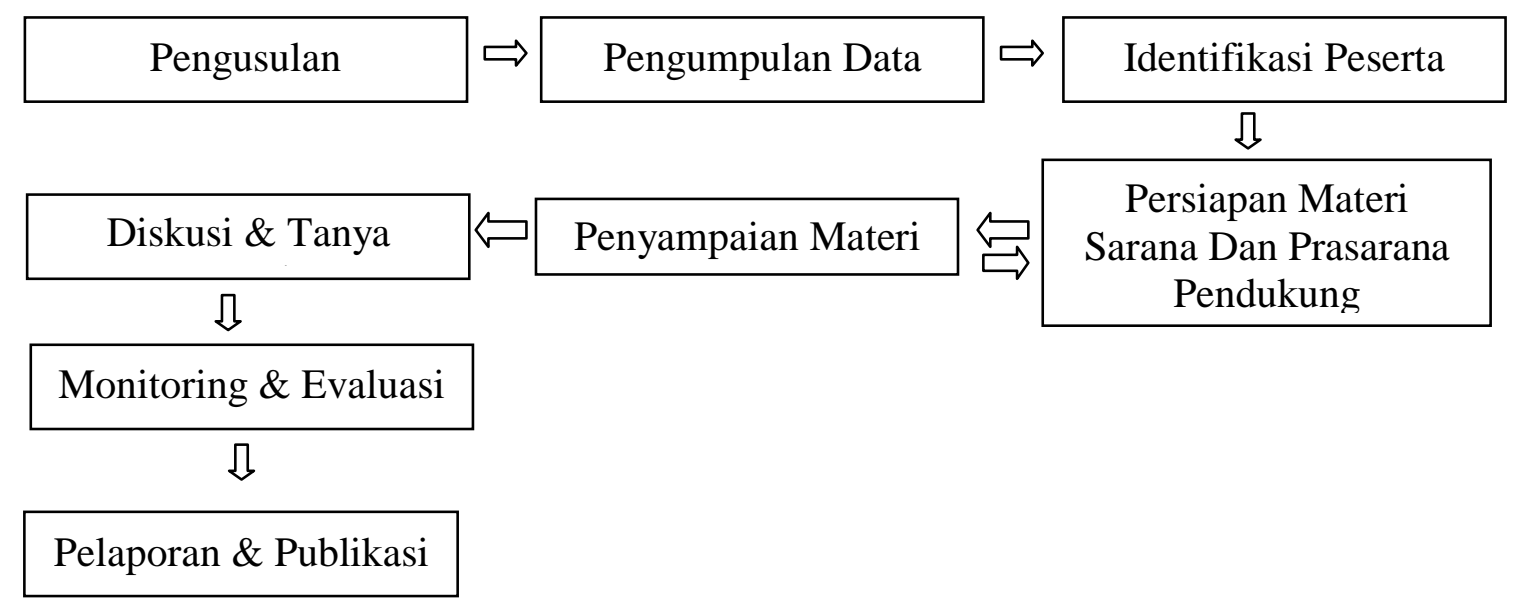

Gambar 1. Alur Kegiatan Pengabdian Kepada Masyarakat

\section{HASIL DAN PEMBAHASAN}

Ilmu ekonomi dapat didefinisikan sebagai ilmu yang mempelajari bagaimana individu dan masyarakat menggunakan sumber daya yang terbatas untuk memenuhi kebutuhannya (Sukirno, Manurung, Raharja)

Ekonomi kreatif merupakan konsep yang menitikberatkan pengembangan nilai tambah suatu barang melalui kreativitas dan inovasi untuk menggerakkan ekonomi. Juga merupakan pengembangan bakat individu yang berdaya kreasi dan daya cipta berdasarkan keterampilan dan kreativitas yang dimiliki (Darwanto, 2015). Definisi ekonomi kreatif menurut Departemen Perdagangan RI yaitu industry kecil dari pengembangan bakat melalui kreativitas dan keterampilan untuk menciptakan lapangan pekerjaan guna kesejahteraan.

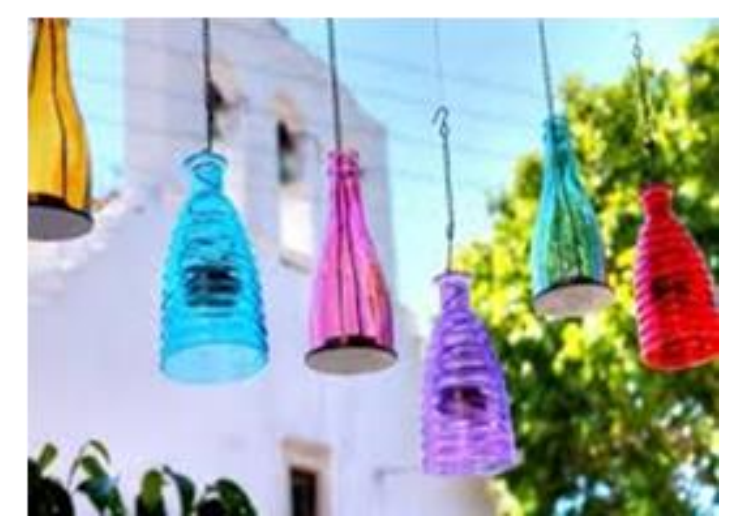

Gambar 2. Foto Hasil Kerajinan Barang Bekas

Sampah merupakan barang yang secara ekonomis sudah tidak bernilai yang dihasilkan oleh kegiatan manusia ataupun dari alam sehingga tidak mempunyai nilai manfaat (Sejati, 2009). Berdasarkan sumbernya, sampah digolongkan bersumber dari pemukiman, tempat dagang, industri dan tempat umum (Sumantri (2010). Sampat juga 190 
BAKTIMAS

Jurnal Pengabdian pada Masyarakat
Vol. 1, No. 4,

Desember 2019
eISSN 2685-113x

pISSN 2685-0303

dapat digolongkan berdasarkan jenis yaitu berdasarkan zat kimia yang terkandung, berdasarkan dapat tidaknya dibakar dan berdasarkan karakteristik sampah (Notoadmodjo, 2007).

Pemicu tingginya volume sampah dari waktu ke waktu salah satunya tingkat konsumsi yang tinggi. Pola konsumsi cepat saji mengakibatkan sampah baik dari volume ataupun jenisnya lebih banyak. Terutama sampah plastic, karena sementara ini plastic merupakan tempat yang paling simple dan mudah didapat, mulai kantong plastic untuk belanja di Mall-Mall sampai botol plastic kemasan dari berbagai olahan makanan dan minuman. Olahan makanan dan minuman cepat saji dengan berbagai varian tidak lagi kota sebagai lahan pasarnya tetapi juga sudah masuk desa-desa di berbagai wilayah. Jika di kota sampah ditangani oleh pasukan kuning, tidak begitu halnya dengan penanganan sampah di desa. Masyarakat desa lebih tradisional lagi dalam penanganan sampah yaitu dengan di bakar atau ditimbuh di pekarangannya. Anak-anak kecil juga kurang mendapatkan pemahaman tentang membuang sampah pada tempatnya. Karena memang belum ada tempat pembuangan akhir, sehingga anak-anak asal saja dalam membuang bekas wadah makanan atau minumannya. Yang terjadi sampah berserakan di sembarang tempat, di pinggir jalan, di sungai, dilahan kosong atau di sekitar rumah.

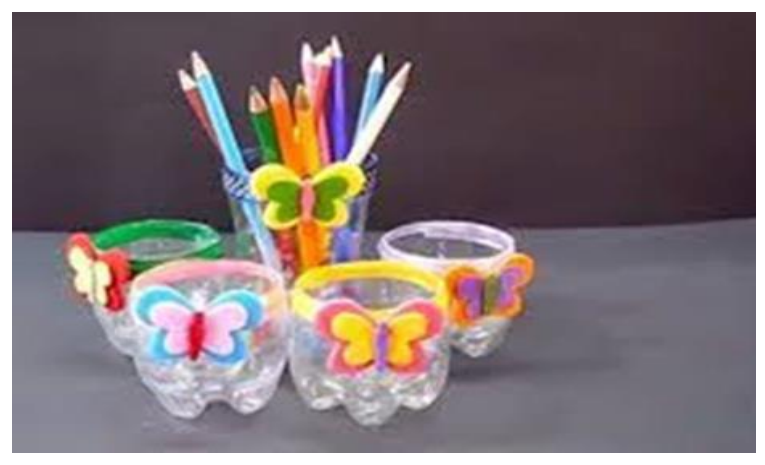

Gambar 3. Foto Hasil Kerajinan dari sampah

Home industry merupakan bagian terkecil dari pengelompokan industry berdasarkan kapasitas pekerja, dimana katagori Home industry hanya memiliki 1- 4 orang dengan aset dan modal belum bisa ditentukan. Secara umum pelaku home industry yang menjadi permasalahan adalah memulai berwirausaha, karena untuk menjadi wirausahawan tidak cukup hanya bermodalkan tekat menjadi wirausahawan tetapi butuh komitmen dan motivasi untuk menjadi wirausahawan. Karena untuk merintis usaha atau membuka usaha home indutry tidaklah semudah membalikan telapak tangan. Jatuh bangun dalam usaha itu hal yang sangat wajar, maka dari itu butuh sumber daya manusia yang berdedikasi, ulet, pantang menyerah, pekerja keras dan berani mengambil risiko. agar home industry nya tetap eksis. Apalagi wirausaha home industry berbahan baku barang bekas tentu butuh daya juang yang luar biasa, karena untuk memasarkan hasil produksinya harus bersaing dengan produksi barang baru yang secara harga juga mampu bersaing. Tentu masyarakat akan cenderung memilih barang baru bukan barang daur ulang. Tapi bukan berarti home industry dari barang bekas ini tidak bisa dikembangkan. Justru perlu diberikan pemahaman, 
Denok Sunarsi, Endang Kustini, Asep Muhammad Lutfi, Rini Dianti Fauzi, Noryani

pengetahuan, pelatihan bagaimana merubah barang bekas menjadi barang yang berdaya guna dan bernilai ekonomis. Sekali dayung dua pulau terlaupaui, gambaran jika sampah diberdayakan tidak saja mampu meningkatkan ekonomi keluarga tetapi sekaligus penanganan sampah secara efektif dan efisien.

Home industry daur ulang barang bekas mungkin belum familier di masyarakat, atau masih dipandang sebelah mata karena bahan bakunya dari barang bekas. Wajar kalau selama ini produk kreatifitas dari daur ulang barang bekas belum mendapatkan tempat di hati masyarakat. Untuk itu perlu mendapatkan perhatian dari pemerintah daerah setempat dan civitas akademika untuk membantu menumbuhkan wirausaha home industry dengan memanfaatkan barang bekas untuk meningkatkan ekonomi keluarga.

\section{Simpulan}

\section{PENUTUP}

Penyuluhan yang bertujuan menumbuhkan jiwa wirausaha di kalangan ibu-ibu ini semata-mata untuk memberikan kegiatan positif bagi ibu-ibu agar waktu luangnya tidak sia-sia. Penyuluhan wirausaha home industry untuk meningkatkan ekonomi keluarga dengan daur ulang barang bekas, hadir untuk memberikan pengetahuan, wawasan dan peluang yang sangat potensial dikembangkan, karena bahan bakunya murah dan mudah diperoleh. Tetapi untuk kegiatan positif yang lebih produktif sehingga dapat meningkatkan ekonomi keluarga.

Hasil kegiatan ini diharapkan dapat turut berkontribusi membangun desa Cidokom melalui ibu-ibu PKK nya berbagi pengetahuan, mendorong masyarakat untuk pengembangan sumberdaya yang dimiliki secara berkelanjutan untuk meningkatkan ekonomi keluarga. Wirausaha home industry daur ulang barang bekas ini dimaksudkan dapat memberikan motivasi bagi masyarakat untuk meningkatkan kemampuannya dan berkarya sehingga mendatangkan manfaat bagi dirinya dan masyarakat sekitar.

\section{DAFTAR PUSTAKA}

Darwanto, 2015. Pengembangan Usaha Mikro Kecil dan Menengah (UMKM) Berbasis Ekonomi Kreatif di Kota Semarang. Undip Semarang

Gunartin, 2019. Gunartin, Analisa Efektifitas Bank Sampah Sebagai Alternatif Pengelolaan Sampah Dalam Upaya Menuju Smartcity di Kota Tangerang Selatan. Jurnal INOVASI Volume VI Nomor 1 Juni 2019

Notoadmodjo, 2007 Pendidikan dan Perilaku Kesehatan. Reneka Cipta. Jakarta. Cetakan ke 2.

Sejati, 2009. Pengelolaan Sampah Terpadu. Yogyakarta.

Sumantri (2010) Kesehatan Lingkungan. Kencana Prenada Media Group. 
BAKTIMAS

Jurnal Pengabdian pada Masyarakat
Vol. 1, No. 4,

Desember 2019
eISSN 2685-113x

pISSN 2685-0303

Sunarsi, D., \& Asmalah, L. (2018). Pelatihan Manajemen Pengembangan Diri Bagi Penerima Beasiswa RZIS UGM Dan Dompet Shalahuddin Jogjakarta. Jurnal Pengabdian Dharma Laksana, 1(1).

Sunasi, D., Kusjono, G., \& Nuryana, I. (2019). Pelatihan Manajemen Penguasaan Kelas Dan Pembuatan Bahan Ajar Bagi Tenaga Pengajar Sukarela Taman Belajar Kreatif Mekarsari. Jurnal Pengabdian Dharma Laksana, 2(1), 41-44. 